\title{
High-risk percutaneous coronary intervention with Impella CP hemodynamic support. A case series and method presentation
}

\author{
Adam Sukiennik ${ }^{1}$, Michał Kasprzak ${ }^{1}$, Wiesław Mazurek ${ }^{2}$, Piotr Niezgoda ${ }^{1}$, tukasz Bednarczyk ${ }^{1}$, Jacek Kubica ${ }^{1}$ \\ ${ }^{1}$ Department of Cardiology and Internal Diseases, University Hospital No. 1, Collegium Medicum in Bydgoszcz, Nicolaus Copernicus \\ University in Torun, Poland \\ 2Department of Cardiology, The Ludwik Rydygier Provincial Polyclinical Hospital, Torun, Poland
}

Adv Interv Cardiol 2017; 13, 1 (47): 67-71 DOI: https://doi.org/10.5114/aic.2017.66189

\section{Introduction}

Advanced age and additional co-morbidities in patients suffering from coronary artery disease (CAD), with complex coronary lesions including multi-vessel and unprotected left main (ULM), preclude surgical revascularization due to high perioperative morbidity and mortality. For such patients, percutaneous coronary intervention $(\mathrm{PCl})$ may be the only alternative, even if there is a significant technical challenge and procedural risk.

Percutaneous hemodynamic support may be favorable during high-risk $\mathrm{PCI}$ [1-3]. Intra-aortic balloon pump (IABP) counter-pulsation is the most commonly used approach. Its benefit of improving long-term survival after high-risk $\mathrm{PCl}$ was confirmed in a recent meta-analysis [4]. However, IABP only modestly increases cardiac output and coronary blood flow, and may provide insufficient circulatory support when a hemodynamic collapse occurs [2, 3]. The Impella CP axial flow pump (ABIOMED Inc., Danvers MA, USA) is another percutaneous device, which offers more effective hemodynamic support compared to $\operatorname{IABP}[5,6]$.

We describe five cases of patients who underwent complex $\mathrm{PCl}$ supported by the Impella CP, which is a novel approach in Poland [7].

\section{Cases report}

Demographic, clinical and procedural data are summarized in Table I. All patients were men with mean age of $78.8 \pm 8.2$ years and mean left ventricular ejection fraction (LVEF) of $29.4 \pm 13.4 \%$. Baseline coronary lesions' localization in angiography and final $\mathrm{PCl}$ results in two illustrative patients are shown in Figure 1. High risk was determined based on clinical presentation with myocardial infarction (MI) (4 patients), impaired LV function, advanced age, significant co-morbidities, chronic heart failure symptoms and complex lesions with unprotected distal left main and multi-vessel disease. The PCI was performed in AUTO mode and all patients received drug-eluting stent (DES), after rotablation in 1 patient. Impella CP was removed in all patients immediately after $\mathrm{PCl}$ and the femoral artery was closed with two Perclose ProGlide (Abbott Vascular, CA, USA) devices. Clinical status has improved in all patients and there were no deaths during 30-day follow-up.

\section{Circulatory support with the Impella CP}

The Impella CP Circulatory Support System is a $14 \mathrm{Fr}$ size micro-axial blood pump, mounted on a $9 \mathrm{Fr}$ catheter, which aspirates the blood from the LV cavity and expels it to the ascending aorta [8]. With its maximal speed of 46,000 revolutions per minute (rpm), the device enhances the blood flow from the LV to the aorta by a maximum of 3.3 to $3.5 \mathrm{l} / \mathrm{min}$ in clinical conditions. In contrast to the IABP, the Impella works independently of cardiac rhythm [3]. The single-use components of the Impella CP system include the Impella CP catheter, 0.018 inch $260 \mathrm{~cm}$ placement guidewire, connector cable, purge cassette and introducer kit containing a $14 \mathrm{Fr}$ peel-away introducer, 8-10-12 Fr dilators and 0.035-inch stiff guidewire for access. The catheter is inserted percutaneously, usually into the femoral artery through a $14 \mathrm{Fr}$ vascular sheath, and can be held in place up to 5 days ( $6 \mathrm{~h}$ in US), according to the manufacturer's recommendation.

The main mechanism of action of the Impella CP is unloading of the LV. As a result, the Impella CP reduces

Corresponding author:

Adam Sukiennik MD, PhD, Department of Cardiology and Internal Diseases, University Hospital No. 1, Collegium Medicum, Nicolaus Copernicus University, 9 M. Skłodowskiej-Curie St, 85-094 Bydgoszcz, Poland, phone: +48 5258540 23, fax: +48 5258540 24, e-mail: adamsukie@gmail.com Received: 10.02.2016, accepted: 6.09.2016. 
Table I. Demographic, clinical and procedural data

\begin{tabular}{|c|c|c|c|c|c|}
\hline Parameter & $\begin{array}{c}\text { Case } 1 \\
\text { (Figures } 1 \mathrm{~A}, \mathrm{~B} \text { ) }\end{array}$ & Case 2 & Case 3 & $\begin{array}{c}\text { Case } 4 \\
\text { (Figures } 1 \mathrm{C}, \mathrm{D} \text { ) } \\
\end{array}$ & Case 5 \\
\hline Age [years], sex & 86, male & 82 , male & 86 , male & 69, male & 71 , male \\
\hline Diagnosis & NSTEMI & NSTEMI & NSTEMI & NSTEMI & UA \\
\hline EF (\%) & $42-45$ & $35-38$ & 37 & 15 & 15 \\
\hline Other risk factors & $\mathrm{DM}, \mathrm{CRD}$ & CHF III, CRD & $\begin{array}{l}\text { CHF III/IV, pleural } \\
\text { effusion, chronic } \\
\text { cerebral ischemia, } \\
\text { stenosis in the left } \\
\text { carotid }\end{array}$ & $\begin{array}{c}\text { CHF III/IV, CRD, } \\
\text { anemia, recurrent VT } \\
\text { with resuscitation, } \\
\text { significant MR }\end{array}$ & CHF III, VT, ICD, \\
\hline $\begin{array}{l}\text { Ischemic ST } \\
\text { depression in the } \\
\text { ECG (leads) }\end{array}$ & I, II, III, V3-V6 & I, aVL, V4-V6 & I, aVL, V5-V6 & Ventricular pacing & Atrial pacing, LBBB \\
\hline $\begin{array}{l}\text { Coronary angiog- } \\
\text { raphy (localization } \\
\text { of critical lesions) }\end{array}$ & $\begin{array}{c}\text { Distal ULM } \\
\text { and bifurcation of } \\
\text { LAD/D1, chronic } \\
\text { occlusion of RCA }\end{array}$ & $\begin{array}{l}\text { Distal ULM and } 3 \text { VD, } \\
\text { chronic occlusion } \\
\text { of RCA. Severe pro- } \\
\text { trusion of under-ex- } \\
\text { panded CX DES to LM }\end{array}$ & $\begin{array}{l}\text { Distal ULM, LAD, CX, } \\
\text { RCA, massive calcifi- } \\
\text { cations }\end{array}$ & $\begin{array}{l}\text { Distal ULM, LAD, } \\
\text { chronic occlusion } \\
\text { of RCA }\end{array}$ & $\begin{array}{l}\text { Distal ULM, } \\
\text { proximal LAD }\end{array}$ \\
\hline Procedure details & $\begin{array}{l}\text { PCI of distal LM and } \\
\text { LAD/D1 bifurcation }\end{array}$ & $\mathrm{PCl}$ of distal LM & $\begin{array}{l}\text { Rotablation of distal } \\
\text { LM and LAD (formerly } \\
\text { two-staged PCI of } \\
\text { RCA with } 5 \text { DES) }\end{array}$ & $\begin{array}{l}\mathrm{PCI} \text { of } L A D \text { and distal } \\
\mathrm{LM} \text { (formerly staged } \\
\text { recanalization of RCA } \\
\text { with implantation of } \\
3 \text { DES) }\end{array}$ & $\begin{array}{c}P C I \text { of distal } L M, L C X \\
\text { and } L A D\end{array}$ \\
\hline Number of DES & 5 & 2 (1 self-expanding) & 3 & 4 (1 self-expanding) & 3 \\
\hline Impella removal & Immediately after $\mathrm{PCl}$ & Immediately after PCI & Immediately after $\mathrm{PCI}$ & Immediately after $\mathrm{PCI}$ & Immediately after $\mathrm{PCI}$ \\
\hline Complications & $\begin{array}{l}\text { Transient worsening } \\
\text { of renal function }\end{array}$ & $\begin{array}{c}\text { Small hematoma } \\
\text { (Impella entry), gout } \\
\text { attack }\end{array}$ & $\begin{array}{l}\text { Small hematoma } \\
\text { (guiding catheter } \\
\text { entry) }\end{array}$ & None & None \\
\hline $\begin{array}{l}\text { Duration of hospi- } \\
\text { talization after PCl } \\
\text { [days] }\end{array}$ & 11 & 4 & 4 & 21 & 4 \\
\hline
\end{tabular}

end-diastolic pressure and wall tension, thus reducing LV work and myocardial oxygen demand [9]. Moreover, the Impella CP decreasing the pulmonary capillary pressure reduces right ventricular afterload, and increasing the aortic pressure increases coronary perfusion. Forward flow through the pump decreases with increasing ventricular-aortic gradient; thus the highest pump flow and motor current occur during systole when the gradient is minimal. This makes characteristic motor current fluctuations during the cardiac cycle. This phasic flow pattern is reported as maximum and minimum flows. It is also used for Impella CP positioning and flow calculation. The flow through the pump is preload dependent and may be decreased in case of low LV pressure, small LV cavity or impaired right ventricular function [8].

Proper positioning of the catheter requires positioning of its inlet about $3.5 \mathrm{~cm}$ below the annulus of the aortic valve $(3 \mathrm{~cm}$ in a small LV) and in the middle of the LV cavity. It is important to keep the catheter away from the mitral valve leaflets, chordae and papillary muscles. Moreover, coiling in the LV cavity must be avoided. The catheter outlet should be placed in the ascending aorta, well above the aortic valve [8].

The Automated Impella Controller (AIC) provides an interface for controlling the function of the Impella CP catheter, fluid purge and backup power during transportation (at least 60 min when fully charged). At the beginning, after the catheter insertion and careful positioning assessment, the pump is started in AUTO mode, which automatically increases the flow rate over $30 \mathrm{~s}$. After this period of time it is necessary to check waveforms on the AIC and the position of the catheter, which has a tendency to be drawn into the ventricle. In AUTO mode the motor speed of the Impella CP is set to achieve the maximum possible flow without causing suction. After $3 \mathrm{~h}$ of operation the controller automatically switches to P-level mode, which can be set from P-1 to P-8 (0-1.7 l/min to $3.0-3.3 \mathrm{l} / \mathrm{min})$. It is important to remember that a setting of $\mathrm{P}-0$ or $\mathrm{P}-1$ will result in retrograde flow when the Impella CP catheter is placed across the aortic valve. While on the Impella CP support, a patient's blood flow inherently loses its pulsatile nature, which may cause 

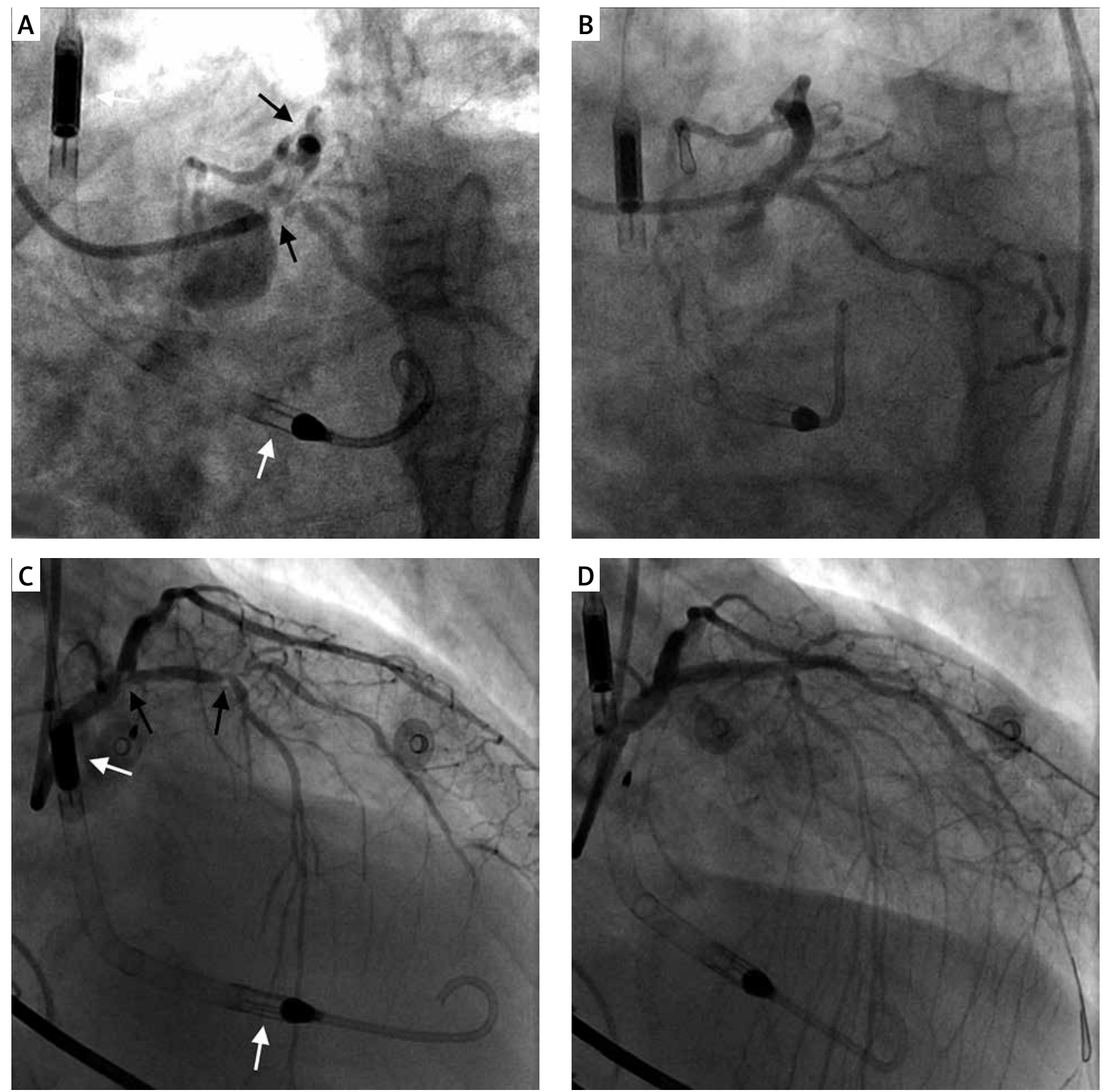

Figure 1. Angiography of the left coronary arteries before and after $\mathrm{PCl}$ of two illustrative patients (treated lesions - black arrows) with the Impella CP in the LV (lower white arrows) and rotary pump in the aorta (upper white arrows)

a patient's pulsatility to drop or disappear completely. As a result, a drastic drop or a "zero" value calculated for $\mathrm{SpO}_{2}$ can be observed, regardless of the true arterial oxygen saturation, adequate mean blood pressure, skin color and arterial blood gas analysis. Reducing Impella CP support, and administering IV fluids to increase blood volume, and/or small doses of ephedrine or phenylephrine, can return pulsatility [8].

During Impella CP support systemic anticoagulation and anticoagulation added to the purge fluid are required. The systemic anticoagulation should prolong activating clotting time (ACT) to $160-180 \mathrm{~s}$ (or > $250 \mathrm{~s}$ during $\mathrm{PCl}$ ) or activated partial thrombin-time (aPTT) adjusted to achieve an ACT target. Because the purge fluid - whether $5 \%$ or $20 \%$ dextrose - contains $50 \mathrm{lU} / \mathrm{ml}$ of heparin, it is important to remember that the patient will also receive a higher rate of infusion of heparin. In the case of heparin-induced thrombocytopenia (HIT), a systemic delivery of an alternative anticoagulant is required, but the Impella CP catheter has not been tested with any alternative anticoagulants in the purge solution [8].

The Impella CP Circulatory Support System is intended for partial circulatory support (e.g. in cardiogenic shock or high-risk $\mathrm{PCl}$ ). It is important to make a care- 
ful clinical assessment before the decision of using the Impeller CP. Performing cardiac echocardiography is advised to exclude thrombus in the LV cavity, which may result in the Impella CP pump stopping. In such circumstances there is also a risk of systemic embolization with LV Impella CP placement, usually due to catheter manipulation in the LV cavity. Severe aortic regurgitation $(\geq 2)$ is a relative contraindication due to increased aortic pressure, which can lead to increase of the aortic regurgitation and LV dilatation. Known or suspected unrepaired abdominal aortic aneurysm, significant descending aorta aneurysm or dissection of the aorta requires special care. Patients with aortic stenosis (orifice area $\leq 1.5 \mathrm{~cm}^{2}$ ) or other abnormal valve performance may be compromised by the use of the Impeller CP. Mechanical aortic valve or heart constrictive devices are contraindications to Impella CP support [8]. Peripheral vascular disease is a relative contraindication, making impossible insertion of a large diameter sheath, even after iliac artery dilatation with a balloon (self-experience). In such cases it is advised to select alternative access depending on the clinical situation. The Impella CP can be removed immediately after successful high-risk PCl. Percutaneous closure devices, such as Perclose ProGlide (Abbott Vascular, CA, USA), can be used, but for long-term implants should be avoided due to infection risk.

If extending cardiac support is necessary after $\mathrm{PCI}$, it is important to disable the AUTO feature and switch to the P-level mode with the highest support (P8), and to disable suction control. The purge system should be transferred to "standard configuration". It is also very important to verify the Impella CP catheter position after installation of the patient in the Intensive Care Unit. The potential complications associated with improper positioning of the catheter include placing the catheter inlet in the ascending aorta, advancing the catheter too far into the LV, and placing the catheter in the papillary muscle. The mentioned inappropriate positions can be well visualized in trans-thoracic cardiac echocardiography (TTE) in the parasternal long-axis projection. The ideal position of the inlet in the LV is approximately $3.5 \mathrm{~cm}$ from the aortic valve. To correct the position of the Impella CP a careful manipulation of the catheter should be done during continuous TTE guidance. The volume status and right ventricular function should also be assessed in TTE. In case of any suspicion of Impella CP displacement, control echocardiography should be performed [8].

Short weaning trials can be performed during observation of LV recovery in echocardiography. If the hemodynamics are stable and only small doses of inotropic support are required, the decision of the final weaning can be made. The support level is gradually decreased over 4-6 h until support is at $1-1.5 \mathrm{l} / \mathrm{min}$. In stable patients the catheter is pulled out into the descending aorta, and after discontinuation of systematic unfractionated heparin the ACT should fall to $\leq 150 \mathrm{~s}$. After $30 \mathrm{~min}$, the AIC can be turned off and the catheter can be removed. A 30-40 min manual compression is almost always sufficient, but direct surgical closure may also be considered [8].

The most common complications are related to the access site (bleeding, infection, limb ischemia) and/or involve stroke, hemolysis, suction episodes and inadequate hemodynamic support.

\section{Discussion}

A decision to use hemodynamic support in our patients was especially difficult, due to the lack of a universal definition of high-risk $\mathrm{PCl}$, and was determined by both the degree of complexity of the coronary artery disease and clinical co-morbidities, such as LV dysfunction, advanced age, diabetes, renal dysfunction and prior procedural history. According to one definition, high-risk PCI is the treatment of an unstable patient with an ejection fraction of less than $25 \%$ or the target vessel supplying more than half of the myocardium [10]. However, the LVEF cut-off value may vary from $25 \%$ to $40 \%$, depending on the expert's opinion [2, 3]. Complex procedures usually require long procedural times and challenging techniques, such as rotational atherectomy, and are more prone to acute vessel occlusion, low-flow or distal embolization and myocardial necrosis. It was demonstrated that partial circulatory support with the Impella CP has been associated with more extensive use of rotational atherectomy and a periprocedural increase of cardiac biomarkers indicative of myocardial injury [5]. The Impella system has been shown to be effective and safe both in high-risk $\mathrm{PCl}$ and $\mathrm{MI}$ complicated by cardiogenic shock (CS). The ISAR-SHOCK trial randomized 26 patients with $\mathrm{MI}$ and CS to IABP or the Impella 2.5. The primary end point (cardiac index change $30 \mathrm{~min}$ after implantation) was higher in the Impella group (0.49 \pm 0.46 vs. $0.11 \pm 0.31 \mathrm{l} / \mathrm{min} / \mathrm{m}^{2}$; $p=0.02$ ), but 30 -day survival was identical (46.2\%) in both groups. No device-related technical failure, major bleeding or ischemia during support was observed. There was only one case of acute limb ischemia requiring surgery in the Impella arm [11]. The PROTECT I trial enrolled 20 stable patients who underwent high-risk PCl. All patients had severely impaired left ventricular function with $\mathrm{EF}<35 \%$ and underwent $\mathrm{PCl}$ of the ULM or last patent coronary artery with Impella 2.5 support. Successful implantation and freedom from hemodynamic compromise during $\mathrm{PCl}$ (primary efficacy endpoint) were observed in all patients. In 30 days follow-up two patients died and two had a periprocedural MI [12]. The Europella registry evaluated 144 stable patients undergoing high-risk $\mathrm{PCl}$ of the ULM, last patent artery or multi-vessel disease with Impella 2.5 support. Mortality was $5.5 \%$ at 30 days (9 patients). Major bleeding requiring transfusion or surgery occurred in 9 patients. There was one stroke and one case of hemolysis requiring transfusion [13]. Another 
large registry that proved the clinical effectiveness of the Impella 2.5 is USPELLA. It is recruiting patients undergoing high-risk elective or urgent $\mathrm{PCl}$ and patients with $\mathrm{MI}$ complicated by CS. The interim analysis, including data of 352 patients, showed a low major adverse cardiovascular event rate (8\%) and high survival rate $(96 \%)$ in the 30-day follow-up (O'Neill WW, TCT 2010). The PROTECT II trial was the first prospective randomized controlled trial comparing the Impella 2.5 versus IABP in patients undergoing non-emergent high-risk $\mathrm{PCI}$ [5]. In the available data of 452 patients randomized before premature discontinuation of the study, the composite primary end point (all-cause death, MI, stroke or transient ischemic attack, any repeat revascularization, need for a cardiac or vascular operation, acute renal insufficiency, severe intra-procedural hypotension, cardiopulmonary resuscitation, ventricular tachycardia requiring cardioversion, aortic insufficiency or angiographic failure of $\mathrm{PCl}$ ) was observed in $35.1 \%$ of the Impella group and in $40.1 \%$ of the IABP group $(p=0.277)$ at 30 days in the intention-to-treat (ITT) population. A non-significantly lower major adverse event rate was observed in the Impella 2.5 supported patients compared with IABP in the ITT population (respectively $40.6 \%$ vs. $49.3 \%, p=0.066$ ) at 90 days. This difference reached statistical significance at 90 days in the per protocol population (respectively $40.0 \%$ vs. $51.0 \%, p=0.023)$. In hemodynamic analysis the Impella 2.5 provided stronger support than IABP $(p=0.001)$.

\section{Conclusions}

Hemodynamic support with the Impella CP device in our high-risk elderly patients was effective, safe and easily removable. With the Impella CP device we were able to perform complex $\mathrm{PCl}$ with a good angiographic result and without intra-procedural complications. It appears to be a feasible strategy in patients undergoing high-risk $\mathrm{PCl}$.

\section{Conflict of interest}

The authors declare no conflict of interest.

\section{References}

1. Windecker S, Kolh P, Alfonso F, et al. 2014 ESC/EACTS Guidelines on myocardial revascularization. Eur Heart J 2014; 35: 2541-619.

2. Rihal CS, Naiduet SS, Givertz MM, et al. 2015 SCAI/ACC/HFSA/ STS Clinical Expert Consensus Statement on the Use of Percutaneous Mechanical Circulatory Support Devices in Cardiovascular Care. J Am Coll Cardiol 2015; 65: e7-26.

3. Myat A, Patel N, Tehran S, et al. Percutaneous circulatory assist devices for high-risk coronary intervention. JACC Cardiovasc Interv 2015; 8: 229-44.

4. Chen S, Yin Y. Short and long term effect of adjunctive intra-aortic balloon pump use for patients undergoing high risk reperfusion therapy: a meta-analysis of 10 international randomized trials. Heart 2014; 100: 303-10.
5. O'Neill WW, Kleiman NS, Moses J, et al. A prospective, randomized clinical trial of hemodynamic support with Impella 2.5 versus intra-aortic balloon pump in patients undergoing high risk percutaneous coronary intervention: the PROTECT II study. Circulation 2012; 126: 1717-27.

6. Burzotta F, Trani C, Doshi SN, et al. Impella ventricular support in clinical practice: collaborative viewpoint from a European expert user group. Int J Cardiol 2015; 201: 684-91.

7. Dudek D, Rakowski T, Sukiennik A, et al. Circulatory support with Impella CP device during high-risk percutaneous coronary interventions: initial experience in Poland. Adv Interv Cardiol 2016; 12: 254-7.

8. Impella CP Circulatory Support System, ABIOMED Instructions for Use \& Clinical Reference Manual. July 2015 Document No. 0048-9001 Rev. G.

9. Sauren LD, Accord RE, Hamzeh K, et al. Combined Impella and intra-aortic balloon pump support to improve both ventricular unloading and coronary blood flow for myocardial recovery: an experimental study. Artif Organs 2007; 31: 839-42.

10. DeVries WC, Anderson JL, Joyce LD, et al. Clinical use of the total artificial heart. N Engl J Med 1984; 310: 273-8.

11. Seyfarth M, Sibbing D, Bauer I, et al. A randomized clinical trial to evaluate the safety and efficacy of a percutaneous left ventricular assist device versus intra-aortic balloon pumping for treatment of cardiogenic shock caused by myocardial infarction. J Am Coll Cardiol 2008; 52: 1584-8.

12. Dixon SR, Henriques JPS, Mauri L, et al. A prospective feasibility trial investigating the use of the Impella 2.5 system in patients undergoing high-risk percutaneous coronary intervention (The Protect I Trial): initial U.S. experience. JACC Cardiovasc Interv 2009; 2: 91-6.

13. Sjauw KD, Konorza T, Erbel R, et al. Supported high risk percutaneous coronary intervention with the Impella 2.5 device the Europella registry. J Am Coll Cardiol 2009; 54: 2430-4. 